
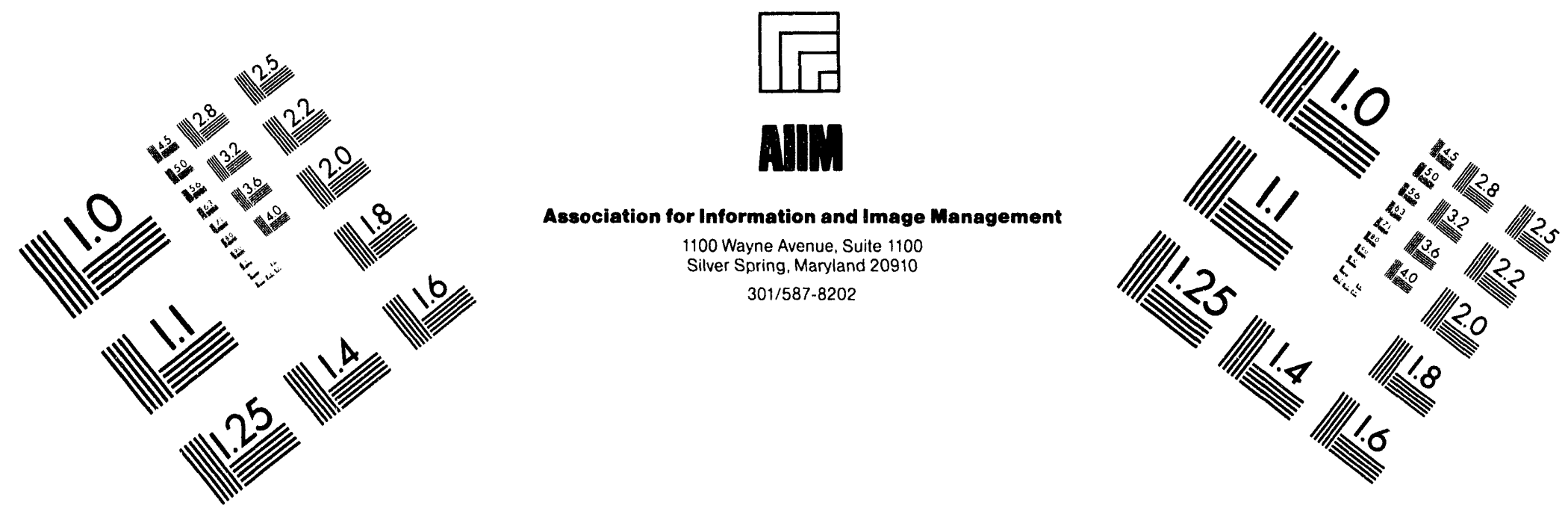

\title{
Centimeter
}

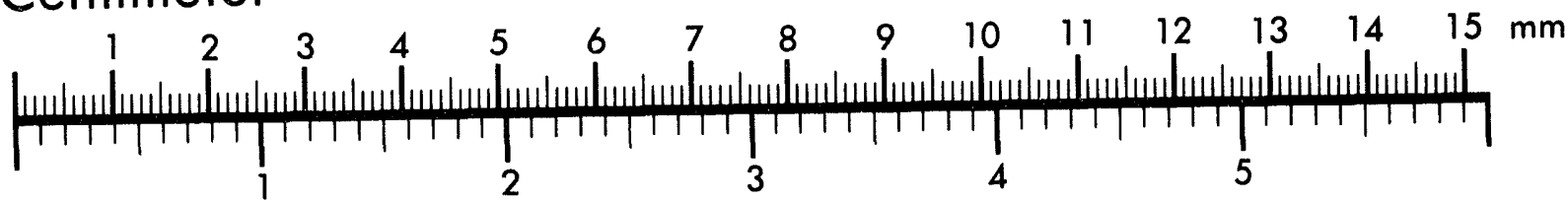

Inches
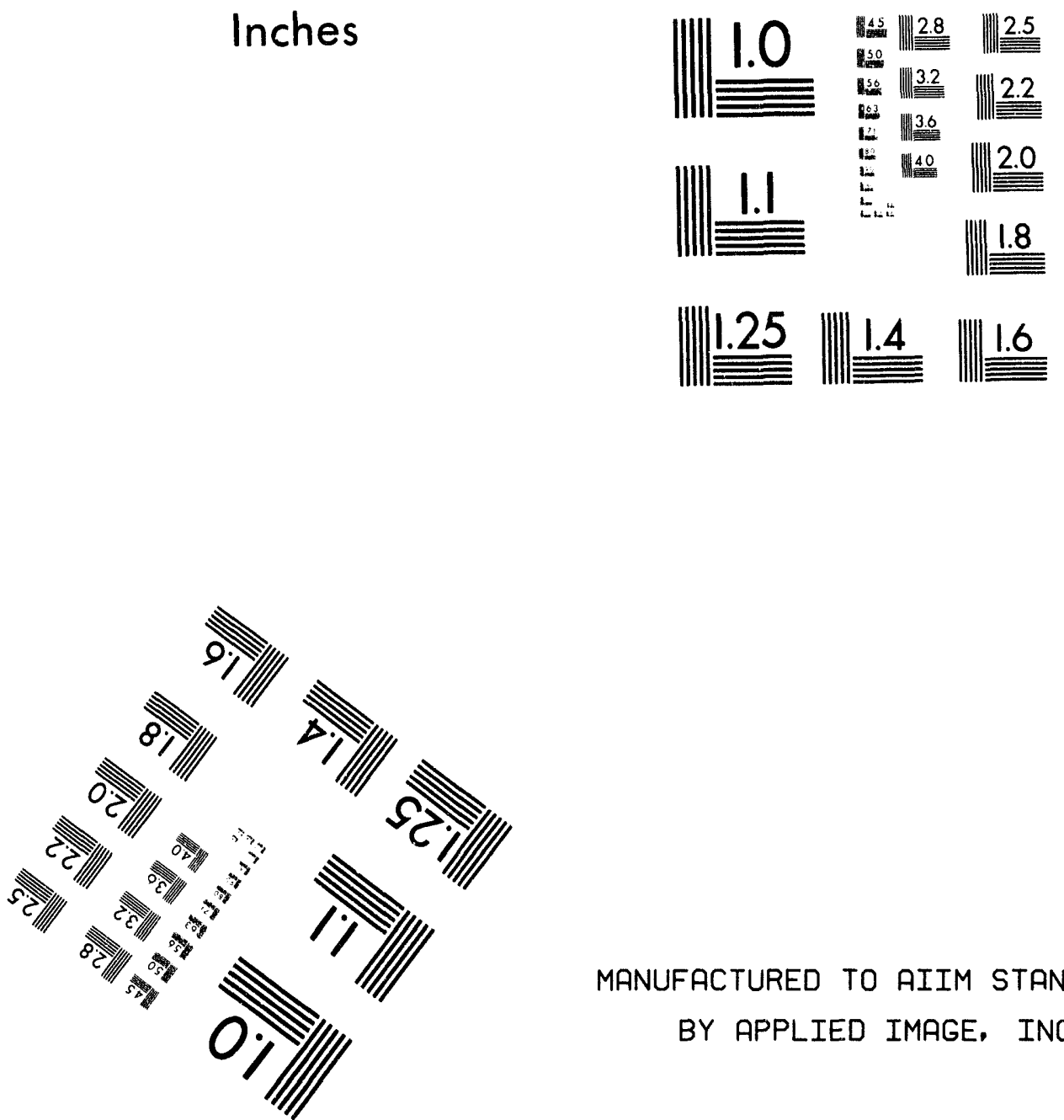

MANUFACTURED TO AIIM STANDARDS

BY APPLIED IMAGE, INC.

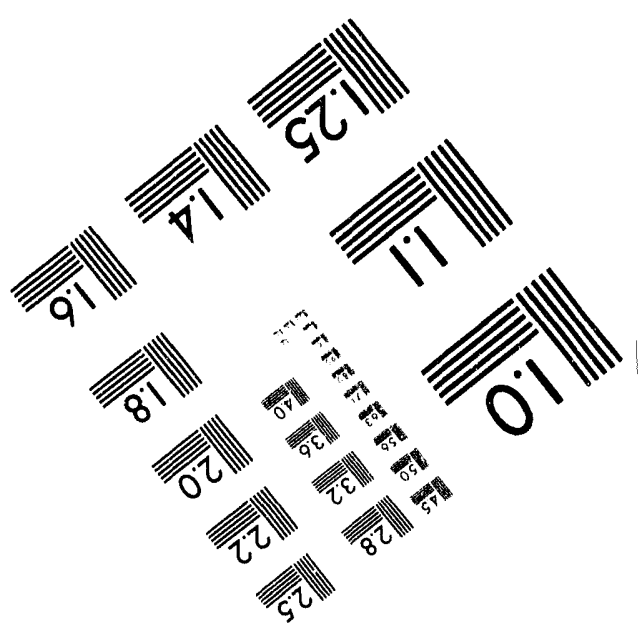



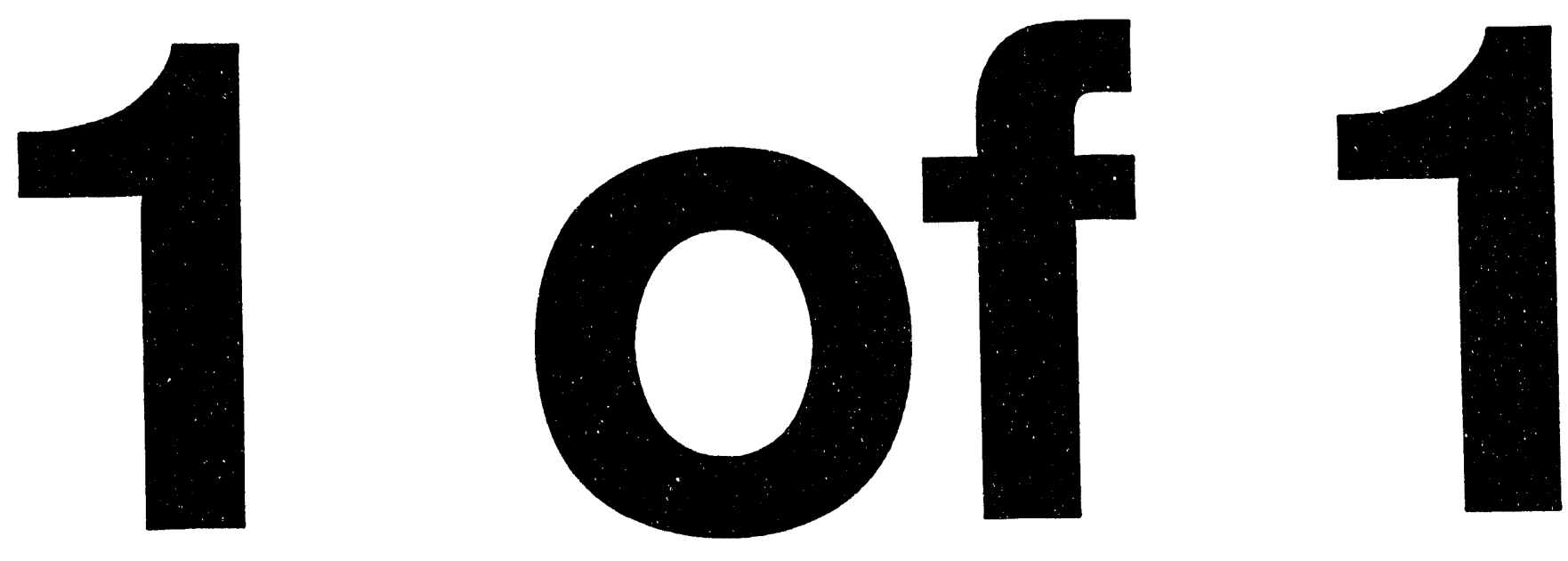


\title{
TEMPERATURE-INITIATED PASSIVE COOLING SYSTEM (TIPACS)
}

C. W. Forsberg and J. C. Conklin

\author{
Mailing Address \\ Charles W. Forsberg \\ CONF-940812--10 \\ Oak Ridge National Laboratory* \\ P.O. Box 2008, 105MTT \\ Oak Ridge, Tennessee 37830-6495 \\ Tel: (615) 574-6783 \\ FAX: (615) 574-3431
}

May 16, 1994

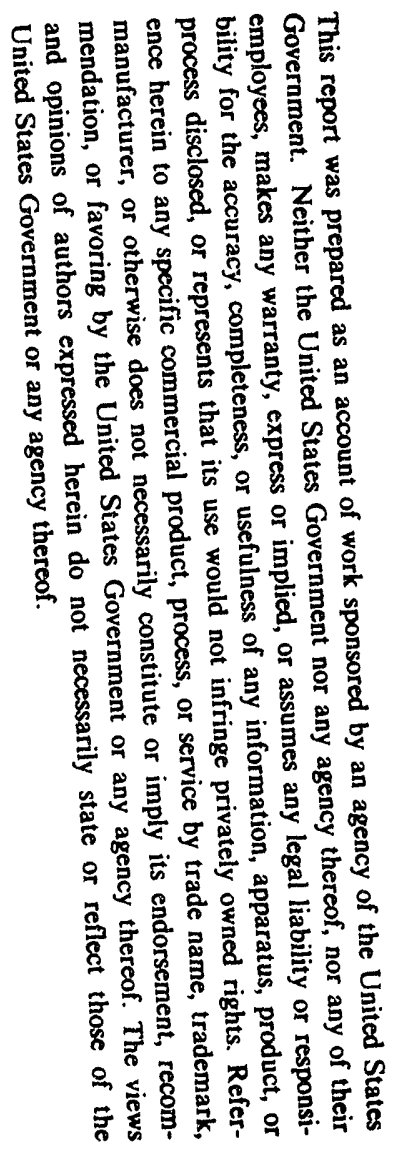

for

Twenty-Ninth Intersociety Energy Conversion

Engineering Conference

Monterey, California

August 7-12, 1994

Conference Topical Area of Paper

Innovative Concepts Session I, NT-03-I

New Technologies for Energy Utilization

Paper 269

Session Chairman: Patrick G. Bailey

Tel: (408) 756-4268; Fax: (408) 742-2461

Time: 9:30-10:00 a.m.; August 10, 1994

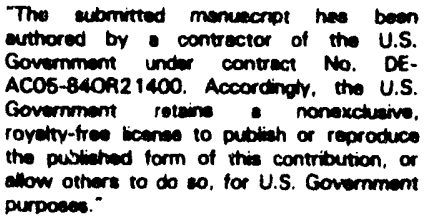

"Managed by Martin Marietta Energy Systems, Inc., under contract DE-AC05-84OR21400 for the U.S. Department of Energy. 


\begin{abstract}
The Temperature-Initiated Passive Cooling System (TIPACS) is a recently invented passive cooling system that transfers heat from a hot, insulated system to a cooler, external environment. TIPACS has four defining characteristics: efficient heat-transfer, passive with no moving components, thermal switch mechanism that allows heat transfer only above a preset temperature, and one-way (heat diode) heat transfer. Example applications include cooling (1) building attics, (2) electrical sheds, (3) chemical reactors, (4) utility-load-leveling batteries, and (5) nuclear reactor containments. TIPACS was evaluated for cooling a modular high-temperature gas-cooled reactor (MHTGR) cavity. The evaluation indicates potential performance and economic advantages.
\end{abstract}

\title{
INTRODUCTION
}

For many domestic, commercial, and industrial facilities, a need exists to cool warm interior environments and dump the heat to the colder, exterior environment. Simultaneously, it is important to avoid overcooling. In some cases, freezing temperatures must be avoided to prevent the freezing of water in pipes. In other cases, reasonable temperatures must be maintained for human habitability or industrial process conditions. Such systems should be passive to eliminate energy consumption, minimize maintenance, and reduce possible failures. A new passive cooling system with these characteristics has been invented (Forsberg 1993)-TIPACS.

TIPACS offers multiple applications. Home attics must be cooled in summer, but it would be desirable to avoid attic cooling in winter. Industrial buildings, such as electronic communication sheds, need to avoid excessive temperatures from internally generated heat loads while maintaining some minimum temperature. For chemical reactors, including batteries, there is an optimum operating temperature. If the temperature is too low, the chemical reactions proceed too slowly (e.g., poor battery performance on cold days). Also, excess temperatures must be 
avoided to prevent unwanted chemical reactions and equipment failure. Last, nuclear reactor containments must be woled to prevent equipment damage from excess heat during both normal and accident conditions while avoiding overcooling and frozen equipment on cold-weather days.

\section{PRINCIPLES OF OPERATIONS}

TIPACS (Fig. 1) consists of two subsystems: a heat-transfer system (HTS) and a temperaturecontrol system (TCS). The HTS is a single-phase, sealed, natural-circulation system that uses a heat-transfer fluid operating just above its vapor-liquid critical point. The vapor-liquid critical point is the state beyond which the difference between the vapor-phase and the liquid-phase no longer exists and only a supercritical-phase exists. Heat generated in the warm enclosure is cooled by the internal TIPACS heat exchanger. The warm, lower-density supercritical fluid inside the internal heat exchanger flows upward to an air-cooled external heat exchanger. The supercritical fluid is cooled as its heat is dumped to the environment through the external heat exchanger, and the cooler, higher-density fluid flows downward back to the internal heat exchanger.

The TCS is a passive device that blocks the flow of fluid if the interior temperature drops below the vapor-liquid critical point. Different startup/shutdown temperatures can be selected by choosing fluids with different vapor-liquid critical points. Because all fluids have critical point temperatures unless they thermally decompose before the critical point is reached, there is a wide choice of options from helium at $-267.96^{\circ} \mathrm{C}$ to mercury at $900^{\circ} \mathrm{C}$. A short list of 41 potential heat transfer fluids was identified in our studies (Forsberg 1994).

For the studies described herein, carbon dioxide $\left(\mathrm{CO}_{2}\right)$ was the operating fluid with its critical point of $31.1^{\circ} \mathrm{C}$. The TCS is the insulated piping and apparatus above the heat exchangers. Below the critical-point temperature, the fluid in the system is partly liquid $\mathrm{CO}_{2}$ and partly gaseous $\mathrm{CO}_{2}$ with the gas-liquid interfaces above the heat exchangers. The gas zone prevents the liquid from flowing around the natural-circulation heat-transfer loop. As the temperature 


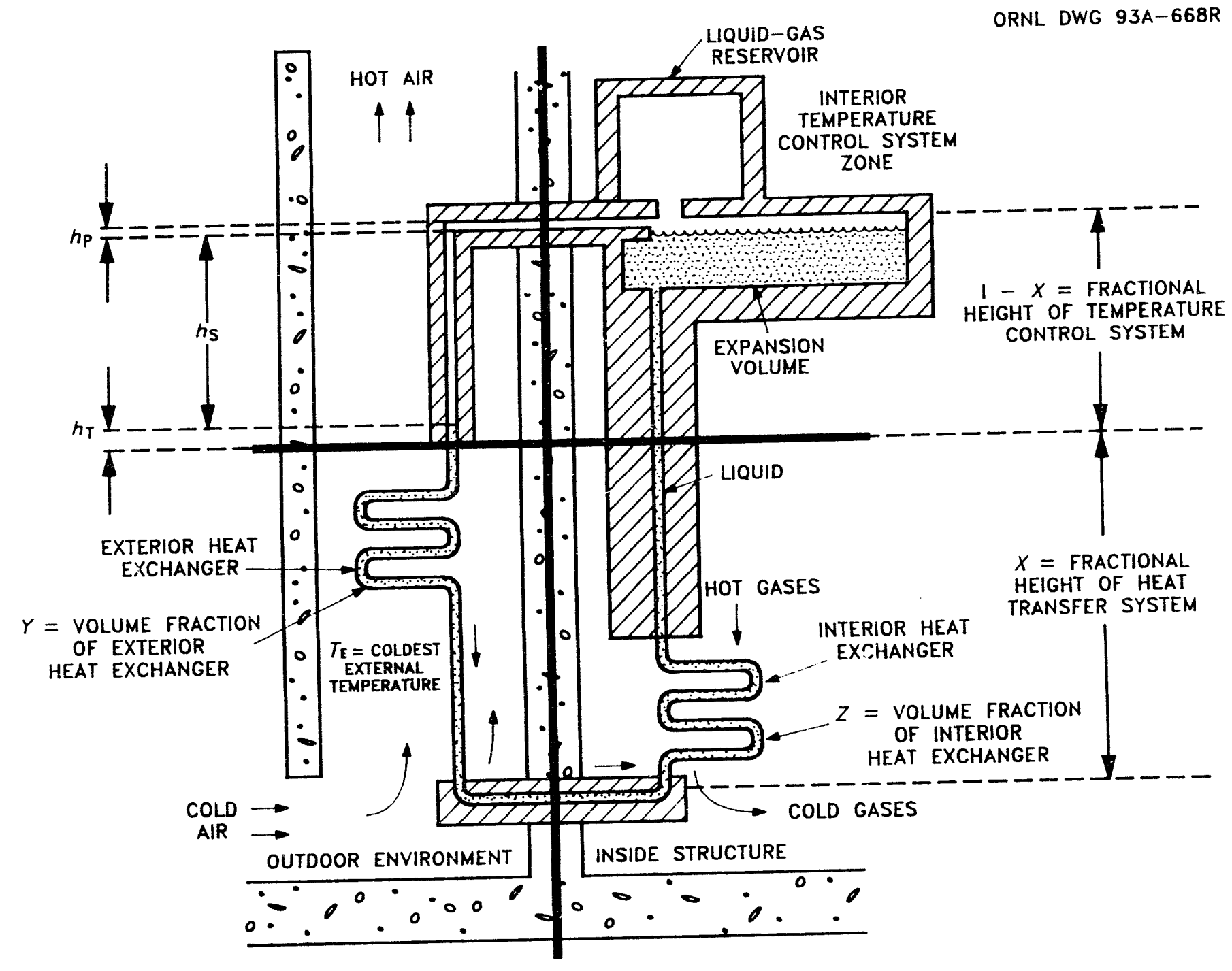

Fig. 1. Schematic of TIPACS model parameters. 
approaches the critical point, (1) the liquid expands to fill the vapor space, (2) the two-phase system then converts to a single-phase supercritical system, (3) the vapor lock is eliminated, and (4) the single phase HTS starts up. This phenomena occurs over a very small temperature range (Table 1 ) because of the rapid changes in fluid density near the critical point.

The TCS piping geometry prevents heat transfer as a two-phase boiling-condensing HTS below the critical-point temperature. Both gas-liquid interfaces are in the insulated piping above the heat exchangers. The liquid at the top of the external heat exchanger is at the outside temperature, but the liquid at the vapor-liquid interface directly above is at the temperature of the internal heat exchanger. Condensing vapor ensures that both vapor-liquid interfaces have the same temperature. The liquid above the external heat exchanger is dynamically stable because warm, low-density liquid rests on top of the colder, higher-density liquid. Heat losses are limited to conduction through this liquid column from vapor-liquid interface to the external heat exchanger.

TIPACS is a heat diode. The outside heat exchanger is at a higher elevation than the inside heat exchanger. If outside temperatures exceed inside temperatures, hot, low-density fluid fills the TCS, while colder, higher-density fluid settles at the bottom of the HTS. This is a stable configuration with no fluid circulation.

\section{CHARACTERISTICS OF TIPACS}

\section{Heat Transfer System}

HTS performance is maximized when (a) the fluid pressure is just above the fluid's critical pressure and (b) the operating temperature range from hot to cold is just above the fluid's critical temperature. This phenomenon is a direct result of the thermodynamic and transport properties of fluids near their critical points. The TCS requires operation in this region to ensure the initiation of the TIPACS at a preset temperature, but, coincidentally, it implies excellent HTS performance. 
Table 1. Density of $\mathrm{CO}_{2}$ near the critical point

\begin{tabular}{ccc}
\hline $\begin{array}{c}\text { Temperature } \\
\left({ }^{\circ} \mathrm{C}\right)\end{array}$ & $\begin{array}{c}\text { Liquid } \\
\left(\mathrm{kg} / \mathrm{m}^{3}\right)\end{array}$ & $\begin{array}{c}\mathrm{Gas} \\
\left(\mathrm{kg} / \mathrm{m}^{3}\right)\end{array}$ \\
\hline & & \\
0 & 929 & 97 \\
5 & 898 & 114 \\
10 & 863 & 134 \\
15 & 823 & 159 \\
20 & 776 & 191 \\
25 & 714 & 238 \\
30 & 601 & 335 \\
31.1 & 468 & 468 \\
\hline
\end{tabular}

Critical point data in bold

Four physical properties primarily determine the performance of a natural-circulation HTS: thermal expansion of the fluid with temperature over its operating ranges, dynamic viscosity, specific heat capacity, and thermal conductivity. These four properties are shown in Fig. 2 for $\mathrm{CO}_{2}$ just above the critical point. In each case, the best fluid properties of any fluid for heat transfer occur near the critical point. Viscosity is at a minimum. The thermal-expansion coefficient, specific-heat capacity, and thermal conductivity are near their maximums. This implies very high performance near the critical point.

\section{Temperature Control System}

The TCS is a thermal switch that imposes some design constraints. TCS operation is dependent upon the expansion of $\mathrm{CO}_{2}$ until a natural-circulation HTS is created. The fluid is both the temperature sensor and control mechanism. If internal temperatures are to control TIPACS, 


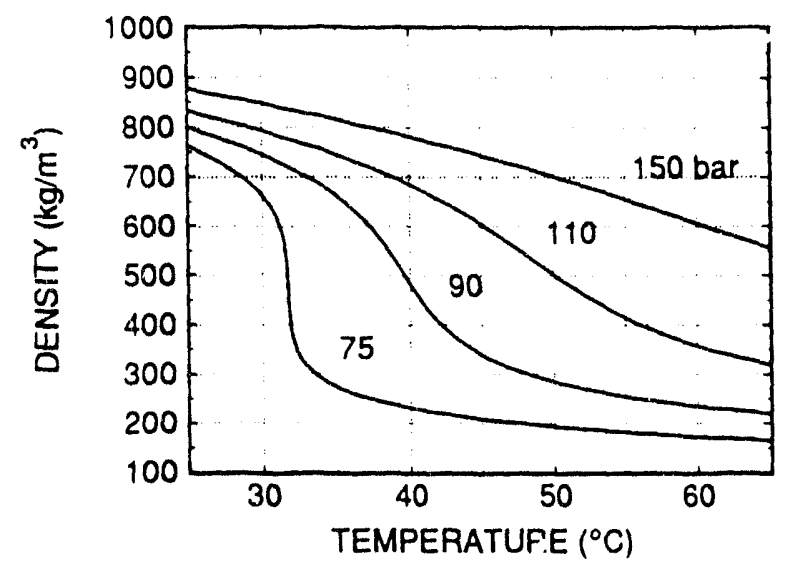

(a) density

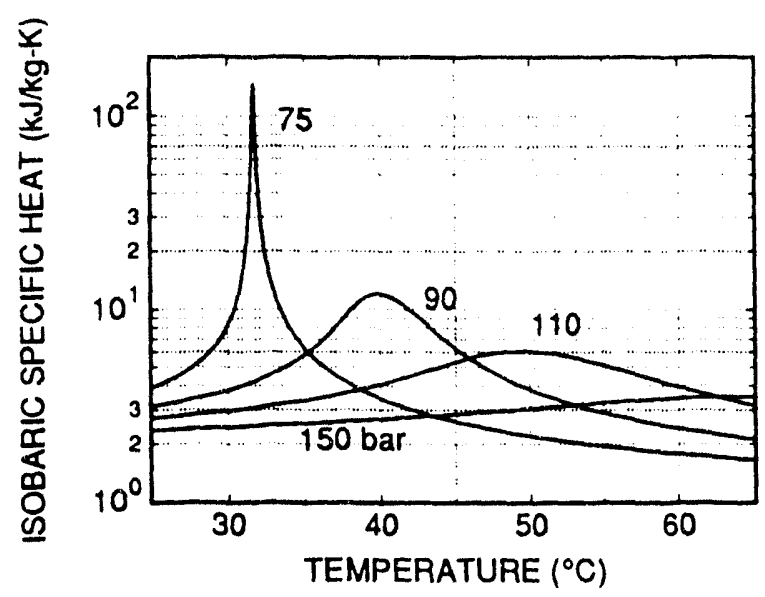

(c) isobaric specific heat

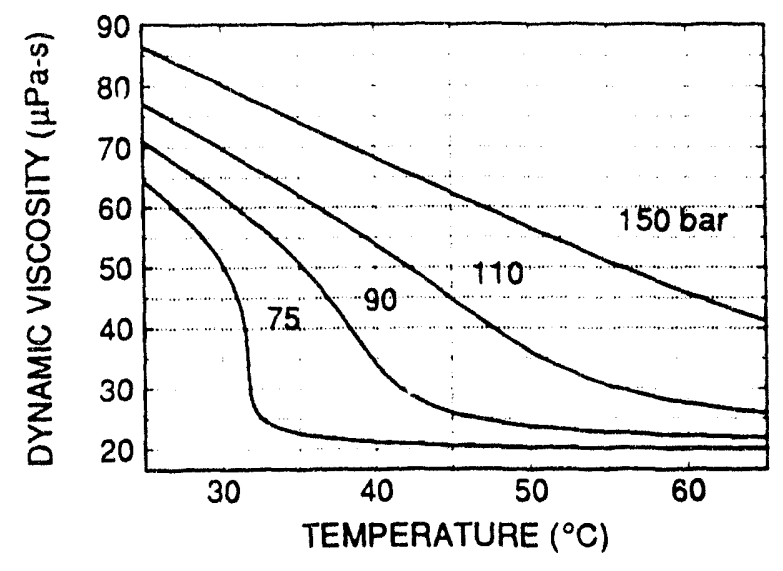

(b) dynamic viscosity

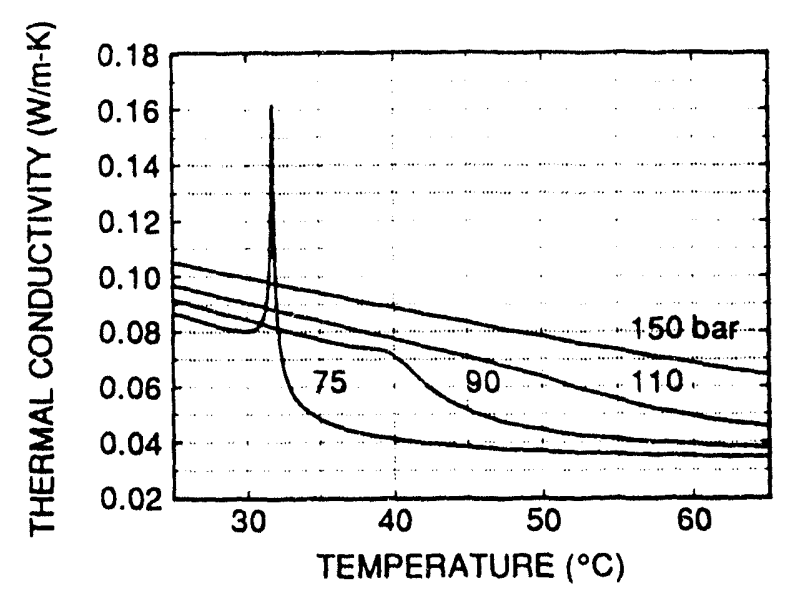

(d) thermal conductivity

Fig. 2 Physical properties of $\mathrm{CO}_{2}$ above the critical point. 
most of the fluid volume must be in the inside zones of the TIPACS. If the normal design of the HTS does not result in most of the liquid residing in the interior zone, more storage volume for the liquid must be added to this zone.

The TCS may contain an expansion reservoir. The expansion reservoir handles the expansion liquid from the exterior heat exchanger from the coldest design conditions to a few degrees below the critical temperature without activating TIPACS. This expansion volume is small because most of the thermal expansion of the liquid that occurs is within a few degrees of the critical point (Table 1).

There is a minimum height of the interior TCS based on the design of the HTS. In a standby mode, the liquid on the inside will be hotter than the liquid on the outside and, hence, have a lower fluid density. To maintain a static balance between the interior (hot) liquid and exterior (cold) liquid, the two liquid heights must vary by height $h_{s}$ (Fig. 1). This implies that the minimum height of the TCS is the sum of the height required for the hot-cold transition zone $\left(h_{T}\right)$ in the outside TCS, some piping height $\left(h_{p}\right)$ and the height $h_{s}$.

The height of the TCS is dependent upon the placement and geometry of the expansion volume. The TCS height is minimized if the expansion volume starts directly above the minimum height and is a wide, shallow vessel (Fig. 1). As a wide, shallow vessel, the height of fluid in the inside TCS volume does not change significantly with expansion or contraction of the liquid. In effect, the height of liquid in the inside TCS is fixed, while the height of liquid in the outside TCS varies.

The TCS may contain a gas-liquid expansion volume above the expansion reservoir. This allows the option of controlled startup of TIPACS from liquid expansion before the critical point is reached. Because of fluid properties and other phenomena, heat-transfer rates are limited compared to operation above the critical point. 


\section{EXAMPLE APPLICATION: MODULAR HIGH TEMPERATURE GAS COOLED REACTOR}

TIPACS was evaluated for cooling an MHTGR reactor vessel and reactor cavity (Forsberg 1994). The design methodology is independent of application, although designs are application specific.

\section{Reactor Design}

The MHTGR is an advanced nuclear power reactor concept with safety systems designed so that safety is not dependent on operator actions. A primary safety issue with any reactor is a cooling failure that allows the reactor core to overheat, results in damages to the nuclear fuel, and permits release of radioactive materials from the reactor core. The MHTGR ensures safety in a unique way. The fuel can withstand temperatures $>1600^{\circ} \mathrm{C}$ before any fuel failure and even higher temperatures before major fuel failure. The basic safety philosophy is to design the reactor sufficiently small such that if all regular cooling is lost, decay heat can be conducted to the surroundings through the steel reactor vessel and then to remove that heat by means of passive systems. This limits the maximum fuel temperature, that in turn, prevents fuel failure and, hence, prevents any release of radionuclides to the environment.

To protect the reactor against external events (storms, sabotage, aircraft collision), the reactor is located in an underground silo (Fig 3). For heat to be transported efficiently to the silo and then to the environment in an accident, the reactor pressure vessel is not insulated. The lack of vessel insulation slightly lowers plant efficiency but improves safety, simplifies design, and lowers total plant costs. The high reactor-exterior-vessel temperatures $\left(>220^{\circ} \mathrm{C}\right)$ during normal operations would damage the concrete silo; thus a reactor containment cooling system is required to protect the silo. The cooling system also limits other equipment damage in the event of a reactor loss-of-cooling accident. The cooler reactor-cavity temperatures provided by TIPACS and conduction of heat to the environment ensures that no release of radioactivity occurs in the event of an accident. 
ORNL DWG 94A-258R

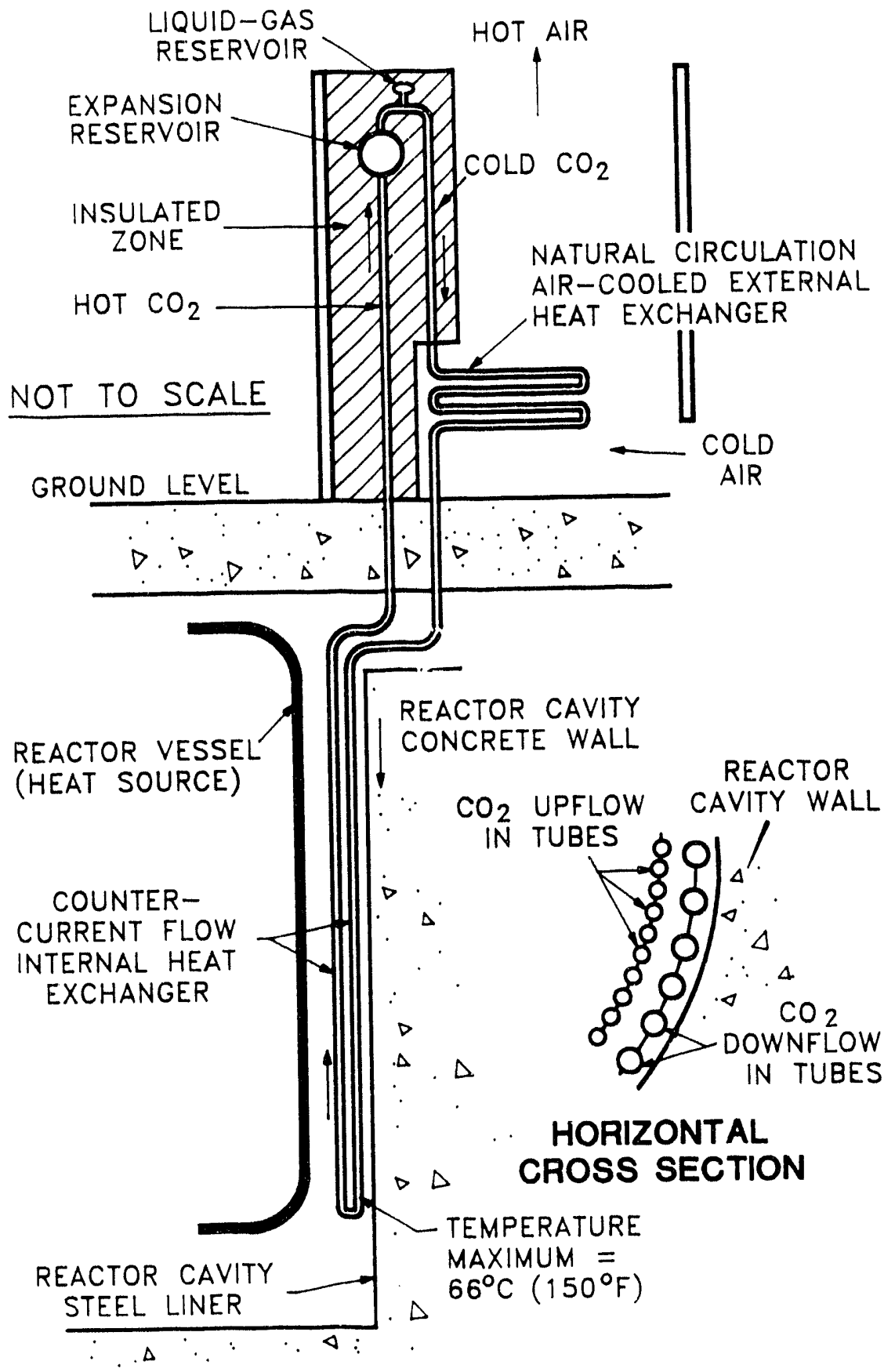

Fig. 3. TIPACS for MHTGR. 


\section{TIPACS Design for the MHTGR}

A conceptual TIPACS design (Table 2) was developed to cool the MHTGR reactor cavity. The external heat exchanger is a standard, horizontal, external-fin tube, four-pass, air-cooled heat exchanger. Carbon dioxide flows inside the tubes along with the natural circulation of air over the outside of the fined tubes. Air circulation past the external heat exchanger is enhanced by a hot-air stack above the heat exchanger.

The internal reactor-cavity heat exchanger consists of two walls of vertical steel pipes between the reactor vessel and concrete-silo wall. Within each group, vertical pipes are connected to each other by steel web. This design is similar to exterior boiler walls (Ganapathy 1993) in large utility fossil fuel boilers. The $\mathrm{CO}_{2}$ enters the pipe wall nearest the concrete silo wall, flows down to the bottom of the reactor cavity, changes direction, and flows up the second pipe wall next to the reactor vessel and then out to the external heat exchanger. During normal operation, the heat exchanger must adsorb heat from the pressure vessel while it keeps concrete containment temperatures below $66^{\circ} \mathrm{C}\left(150^{\circ} \mathrm{F}\right)$ to avoid concrete degradation. Depending upon the design of the MHTGR, the reactor vessel temperature may vary between 220 and $450^{\circ} \mathrm{C}$. Most of the heat removed $(>80 \%)$ is by radiant-heat transfer. The pipe wall next to the reactor removes $>95 \%$ of the heat and is a thermal shield for the other pipe wall. The two walls are needed to control concrete temperatures.

\section{Design Methodology}

A numerical model, based on earlier numerical models to evaluate alternative reactor-cavitycooling options (Conklin 1990), was used to design the HTS. National Institute of Standards and Technology properties for $\mathrm{CO}_{2}$ were used (Friend 1994). A series of preliminary design optimization studies were completed. The TCS design was based on a series of analytical models ol its performance. 
Table 2. Design parameters for representative TIPACS design for MHTGR

\section{MHTGR design parameters}

Thermal power

$450 \mathrm{MW}(\mathrm{t})$

Electrical power

$170 \mathrm{MW}(\mathrm{e})$

Pressure vessel height

$17.4 \mathrm{~m}$

Pressure vessel diameter

Reactor cavity circumference

Reactor cavity (silo) diameter

$10.2 \mathrm{~m}$

\section{TIPACS system design}

Number of TIPACS per reactor

Minimum external air temperature

$-40^{\circ} \mathrm{C}$

Maximum external air temperature

Startup temperature (liquid startup)

Full-operating temperature (supercritical)

Maximum operating pressure

TIPACS physical dimensions

Height

Internal heat exchanger

$17.4 \mathrm{~m}$

Top of internal heat exchanger to ground level

$4.5 \mathrm{~m}$

External heat exchanger above ground level

$5.0 \mathrm{~m}$

External heat exchanger

$1.0 \mathrm{~m}$

Air duct above external heat exchanger

$24.0 \mathrm{~m}$

Total

$52.0 \mathrm{~m}$

External $\mathrm{CO}_{2}$ pipe diameter

$0.5 \mathrm{~m}$

\section{TCS design parameters}

Fractional height $(x)$ of HTS

Fractional height $(1-x)$ of TCS

Internal volume fraction of internal heat exchanger

Internal volume fraction of external heat exchanger 
Table 2. Design parameters for representative TLDACS design for MHTGR (continued)

Internal heat exchanger

Type

Height

Silo-circumference covered

Surface area facing reactor vessel

Downflow-pipe diameter

Downflow-pipe size

Number of downflow-pipes

Upflow-pipe diameter

Upflow-pipe size

Number of upflow pipes
Vertical pipe

$17.4 \mathrm{~m}$

$$
8.0 \mathrm{~m}
$$

$139.2 \mathrm{~m}^{2}$

2 in.

Schedule 80

163

2 in.

Schedule 80

163

\section{External heat exchanger}

Type

Air-cooled multipass cross counterflow

Air passes

$\mathrm{CO}_{2}$ passes

4

Dimensions

Height

$1 \mathrm{~m}$

Width

$8 \mathrm{~m}$

Length

$4 \mathrm{~m}$

Pipe size

2 in.

Pipe thickness

Schedule 80

Pipe length (4 passes)

$16 \mathrm{~m}$

Number of parallel pipes

321

Fin pitch

$346 \mathrm{~m}^{-1}$

Fin height

$18 \mathrm{~mm}$ 
Table 2. Design parameters for representative TIPACS design for MHTGR (continued)

\section{Operational Characteristics}

Exit air temperatures

Vessel at $220^{\circ} \mathrm{C}$

$58.1^{\circ} \mathrm{C}$

Vessel at $450^{\circ} \mathrm{C}$

$189.2^{\circ} \mathrm{C}$

Mass air-flow rate

Vessel at $220^{\circ} \mathrm{C}$

$8.9 \mathrm{~kg} / \mathrm{s}$

Vessel at $450^{\circ} \mathrm{C}$

$6.0 \mathrm{~kg} / \mathrm{s}$

$\mathrm{CO}_{2}$ system pressure drop, $\Delta \mathrm{P} / \mathrm{P}$

Vessel at $220^{\circ} \mathrm{C}$

0.0091

Vessel at $450^{\circ} \mathrm{C}$

0.0103 


\section{Performance}

The performance of a TIPACS unit for cooling one quadrant of an MHTGR reactor cavity is shown in Figs. 3 and 4 for the system as described in Table 2. The radiant-heat flux to TIPACS varies from 1.5 to $6.3 \mathrm{~kW} / \mathrm{m}^{2}$ for reactor-vessel wall temperatures from 220 to $450^{\circ} \mathrm{C}$.

Performance is high for the given conditions, particularly at lower operating temperatures. The preliminary assessment indicates significant potential performance and economic advantages over alternative systems.

\section{STATUS: AND OBSERVATIONS}

A new type of passive cooling system has been invented-TIPACS. Numerical and analytical studies indicate feasibility and high performance. The next step is to build a test loop to confirm the characteristics identified by analysis. The technology has multiple potential applications for cooling: building attics, batteries, chemical reactors, and nuclear-power reactors. Actual designs can be as simple as a curved pipe with the appropriate geometry and with both ends welded to each other or as complex as designs for high power industrial applications. 


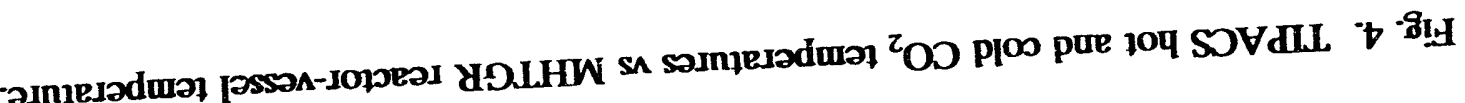

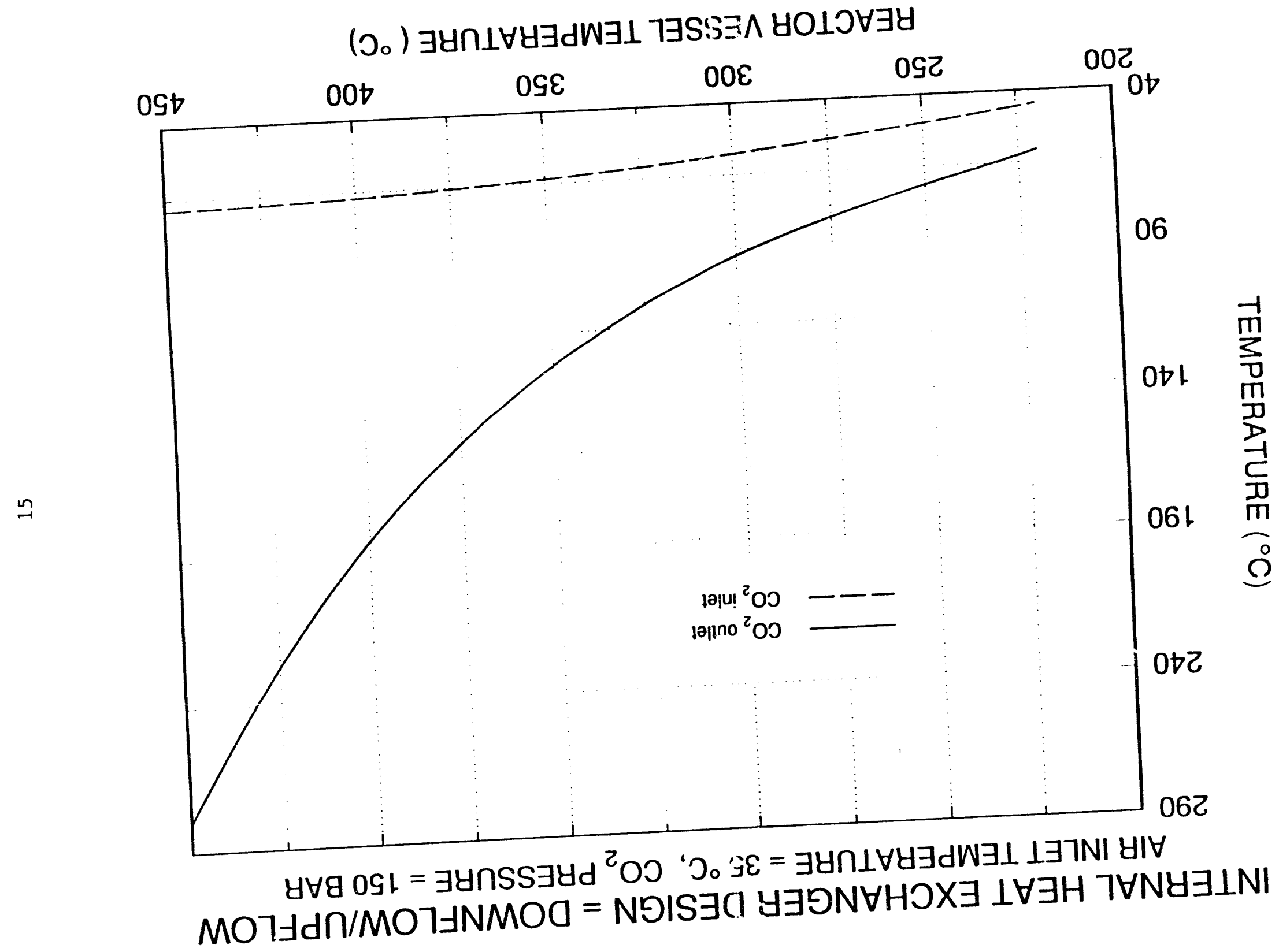


INTERNAL HEAT EXCHANGER DESIGN = DOWNFLOW/UPFLOW
AIR INLET TEMPERATURE $=35^{\circ} \mathrm{C}, \mathrm{CO}_{2}$ PRESSURE $=150 \mathrm{BAR}$

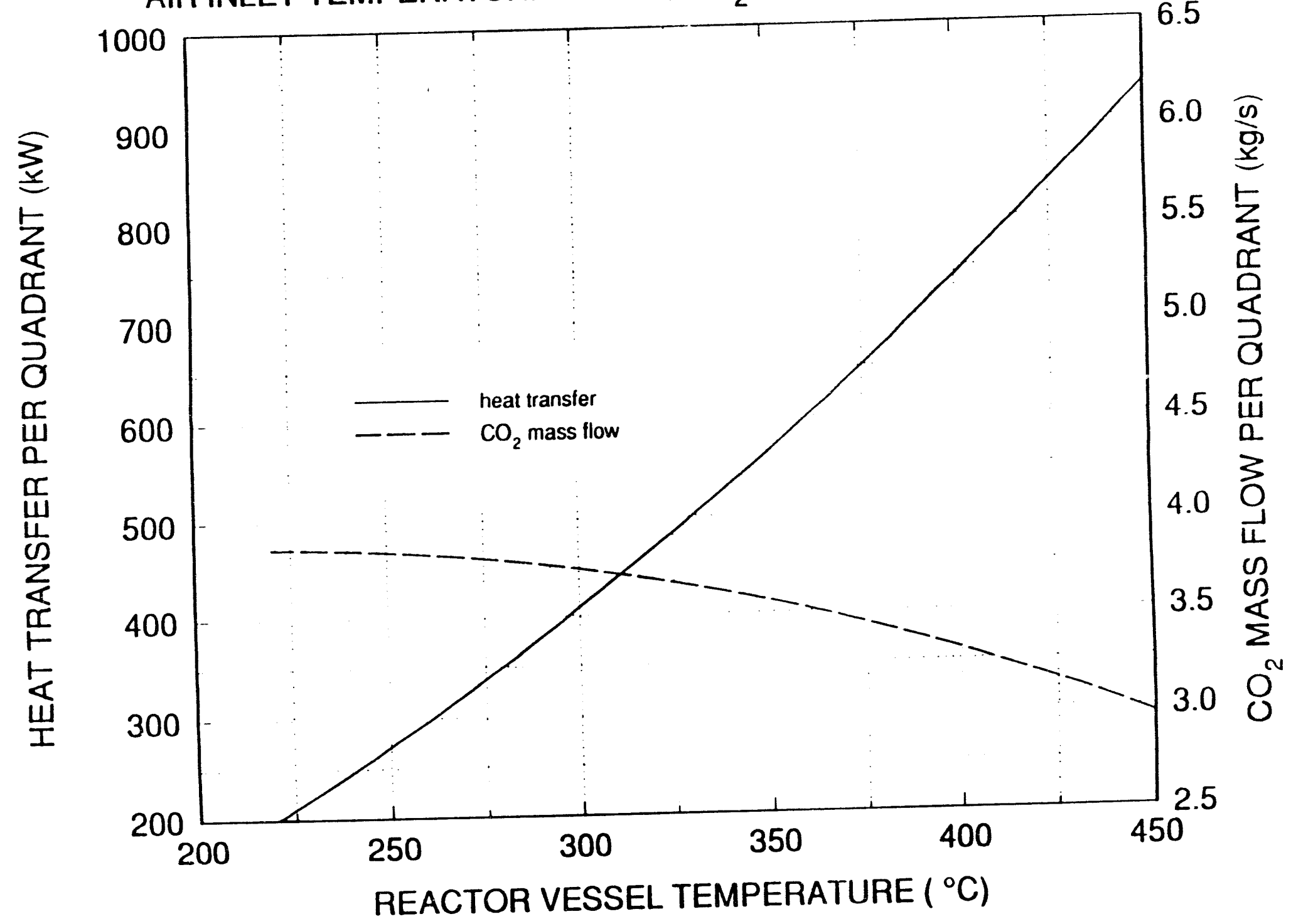

Fig. 5. TIPACS $\mathrm{CO}_{2}$ mass-flow and heat-removal rate from one quadrant of a MHTGR reactor cavity vs vessel temperature. 


\section{REFERENCES}

Conklin, J. C., Modeling and Performance of the MHTGR Reactor Cavity Cooling System NUREG/CR-5514, ORNL/TM-1145, Martin Marietta Energy Systems, Inc., Oak Ridge National Laboratory, Oak Ridge, Tennessee, 1990.

Forsberg, C. W., "Temperature Initiated Passive Cooling System," Patent application to the U.S. Commissioner of Patents and Trademarks, 1993.

Forsberg, C.W., Conklin, J. C., and Reich, W. J., Use of a Temperature-Initiated Passive Cooling System (TIPACS) for the Modular High-Temperature Gas-Cooled Reactor Cavity Cooling System (RCCS), ORNL-6767, Martin Marietta Energy Systems, Inc., Oak Ridge National Laboratory, Oak Ridge, Tennessee, 1994

Friend, D. G., NIST Thermophysical Properties of Pure Fluids, Version 3.0, National Institute of Standards and Technology, Gaithersburg, Maryland, 1992.

Ganapathy, V., "Specify Packaged Steam Generators Properly," Chem. Eng. Prog. 89(9), 62 (September 1993). 

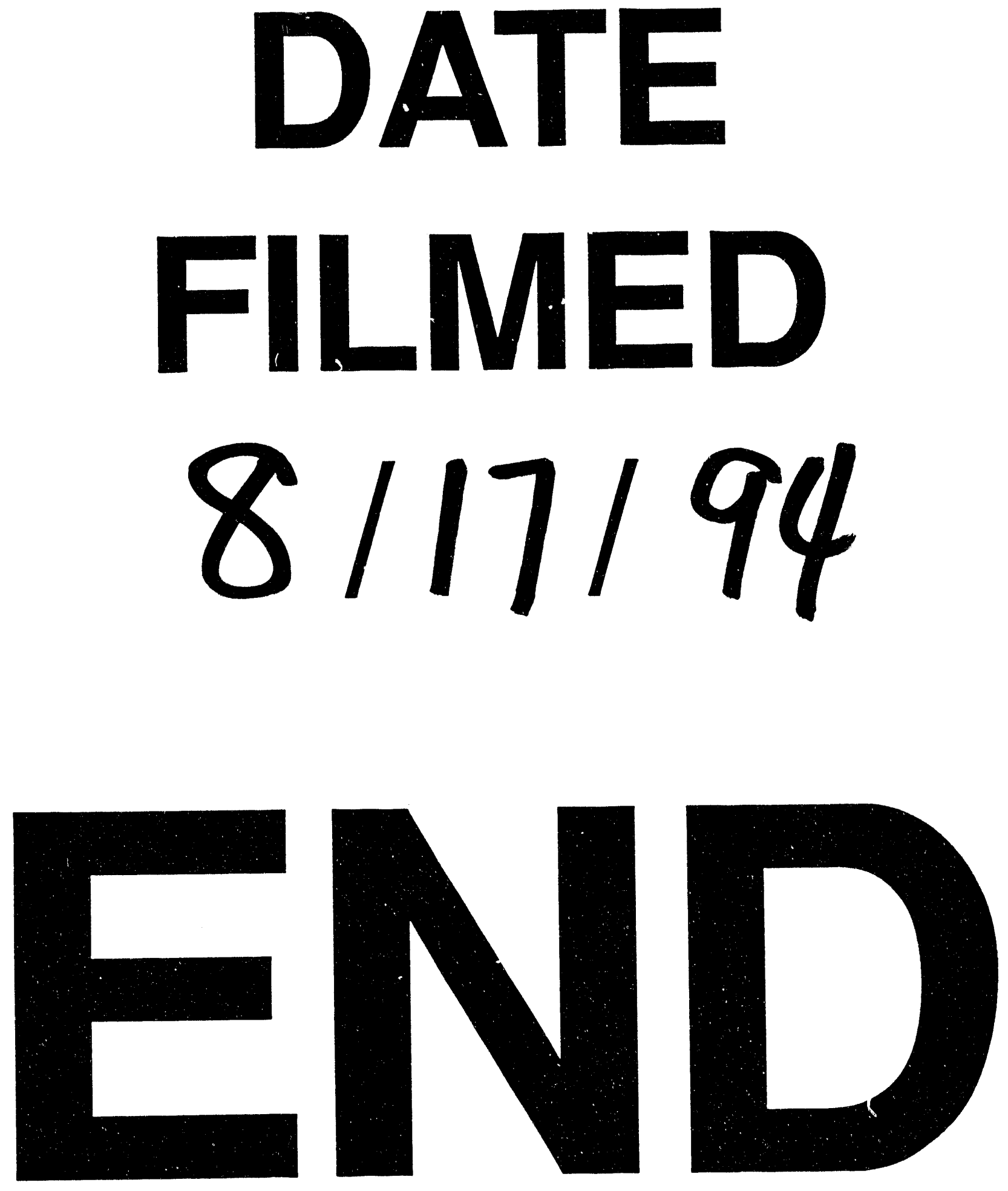
